\title{
Slow Pyrolysis of Biomass in Acidic or Metallic Catalysis
}

\begin{abstract}
MIHAELA BOMBOS ${ }^{1}$, ELENA EMILIA OPRESCU1,2*, CATALINA CALIN², GABRIEL VASILIEVICI ${ }^{1}$, SANDA VELEA ${ }^{1}$, DORIN BO MBOS ${ }^{2 *}$
${ }^{1}$ National Institute for Research Development for Chemistry and Petrochemistry- ICECHIM-Bucuresti, 202

Splaiullndependentei, 060021, Bucharest, Romania

2Petroleum-Gas University of Ploiesti, 39 Bucuresti Blvd., 100680 Ploiesti, Romania

Achieving the process of pyrolysis of biomass in mild conditions is a viable option for optimizing yield in liquid products and reducing coke yield. The partially dried digestate was stabilized by suspending in a reverse emulsion containing the lipid fraction resulting from the processing of the crude digestate, a hydrophobic surfactant of the polyethoxylated castor oil type and a hydrophilic sorbitol-polyethoxylated fatty acid ester type. The pyrolysis of the digestate was carried out in a continuous system, in a quartz tubular reactor, positioned in the central area of a vertical furnace provided with an automatic temperature control system. The experimental program was performed in the presence of two catalysts, $\mathrm{Cu}$ and respectively polyphosphoric acid at atmospheric pressure, temperature in the isothermal reaction zone $460^{\circ} \mathrm{C}$ and liquid hourly space velocity of $0.33 \mathrm{~h}^{-1}$. The composition of the liquid fractions obtained on the two catalysts differs by the presence of a higher concentration of branched isomers in the case of the polyphosphoric acid catalyst.
\end{abstract}

Keywords: algal biomass, pyrolysis, coal, catalyst

With the industrial revolution, the energy consumption of fossil fuels has increased, but also the impact on the environment, with the need for alternative raw materials. Biomass is made up of carbon as one of the bestrenewable solutions for the replacement of fossil resources such as energy applications for heat production, energy and fuels [1], production of chemicals, pharmaceuticals, surfactants, organic solvents, fertilizers), etc [2]. The use of biomass requires several steps of the raw material to exploit the entire biomass content, a promising alternative would be thermochemical processes (gasification, pyrolysis and burning). The synthesis of bio-oil by fast pyrolysis leads to generally too high oxygen contents of the product obtained, which implies further processing thereof $[2,6]$.

Increased potassium concentration favors the increase of biomass reactivity in the pyrolysis process probably due to decreased cellular crystallinity, leading to a reduction in yield in solids with increased potassium concentration. Thus, potassium is both a catalyst for the thermo-chemical conversion of biomass but, because it will be found in bio coal, it will be also an important fertilizer, playng an essential role in plant growth.

Lignocellulosic biomass can be transformed into biofuel, pyrolytic coal and a mixture of gaseous products $\left(\mathrm{CH}_{\text {, }}\right.$ $\mathrm{CO}_{2}, \mathrm{CO}, \mathrm{H}_{2}$, etc). The biofuel obtained can notbe marketed because it does not meet certain quality conditions such as high corrosivity, thermal instability, high oxygen content, lower calorific value, and high temperature instability. To address these disadvantages, the biofuel obtained is subjected to a hydrodeoxygenation process, which involves high hydrogen consumption [7-11].

The mechanism of the catalytic pyrolysis process includes depolymerization, defragmentation, and carbon formation reactions. It depends on the types of biomass and the nature of the catalysts used. Generally, biofuel has obtained a complex mixture containing alcohols, ketones, aldehydes, phenols, ethers, esters, sugars, furans, alkenes, nitrogen compounds and other oxygenated compounds.

The rapid pyrolysis process involves the decomposition of biomass at a reduced reaction time when bio-oil, coal and gas are obtained. Bio oil obtained has a caloric power of about half that of conventional fuel. Rapid pyrolysis is achieved by obtaining a high yield of bio-oil and a low ash content. The essential features of a rapid pyrolysis process for producing liquids are: $i$ ) low thermal conductivity implies a poor heat transfer that diminishes the heating rate and implicitly the reaction rate, requiring reduced biomass size, usually less than $3 \mathrm{~mm}$; ii) the pyrolysis reaction temperature is recommended to be around $500{ }^{\circ} \mathrm{C}$ to maximize bio-oil yield; iii) short reaction times (less than 2 s) to minimize side reactions; $i v$ ) rapid removal of deposited coal to reduce the temperature gradients and implicitly to minimize cracking of vapors; v) rapid cooling of pyrolysis vapors to improve yield in biofuel.[10]

A cheap source of biomass processed through pyrolysis in fuel was sugar cane. Pyrolysis of this raw material was studied comparatively by two methods of pyrolysis, rapid pyrolysis and slow pyrolysis respectively. These methods differ by the thermal decomposition process performance of biomass to fuel and by the yields in the reaction products. The studies were conducted at three different temperatures 480,580 and $680^{\circ} \mathrm{C}$. The yields in the reaction products were influenced by the type of pyrolysis and the reactor temperature. Thus the results showed that in the case of slow pyrolysis a higher synthesis gas yield is obtained at higher temperature values. It has also been observed that in the case of rapid pyrolysis, production in solid products increases with increasing temperature. Gases from the thermal decomposition of biomass were $\mathrm{H}_{2}, \mathrm{CO}, \mathrm{CO}_{2}, \mathrm{CH}_{4}$ and some hydrocarbons such as $\mathrm{C}_{2} \mathrm{H}_{4}$ and $\mathrm{C}^{2} \mathrm{H}_{6}$. Lower temperatures have favored methane yields, while higher temperatures have favored hydrogen output. Hydrogen yield increases with temperature rise for both processes; the maximum value was obtained by rapid pyrolysis at $680^{\circ} \mathrm{C}$ (approximately $45 \%$ vol.), while the methane yield depends on the temperature and the type of process, the maximum value being obtained by pyrolysis at $580^{\circ} \mathrm{C}$ (approximately $30 \%$ by volume) [12].

The process of pyrolysis of the biomass in a continuous system involves conditioning it in the form of a suspension in order to optimally load the tubular reactor. In this study the influence of acidity and the nature of the catalysts on 
the pyrolysis process of an digestate from anaerobic digestion was studied.

\section{Experimental part}

The partially dried digestate was stabilized by suspending in a reverse emulsion containing the lipid fraction resulting from the processing of the crude digestate, a hydrophobic surfactant of the polyethoxylated castor oil type and a hydrophilic sorbitol-polyethoxylated fatty acid ester type. The caracteristics of grinded digestate and lipid fraction used in the experiment are shown in [13]. Preparation of digestate suspension was carried out in a balloon fitted with a variable speed stirring system, at a speed of $2000 \mathrm{rpm}$. The composition of emulsified digestate is presented in table 1[13].

Table 1

COMPOSITION OF THE DIGESTATE SUSPENSION

\begin{tabular}{|c|l|c|}
\hline $\begin{array}{c}\text { No. } \\
\text { crt. }\end{array}$ & \multicolumn{1}{|c|}{ Component } & $\begin{array}{c}\text { Concentration, } \\
\text { \%wt }\end{array}$ \\
\hline 1 & Powdery digestate & 20.0 \\
\hline 2 & Distilated water & 7.8 \\
\hline 3 & Lipid fraction & 70.2 \\
\hline 4 & 10EO Castor oil & 2.0 \\
\hline
\end{tabular}

The pyrolysis of the digestate was carried out in a continuous system, in a quartz tubular reactor, positioned in the central area of a vertical furnace provided with an automatic temperature control system. The quartz tube had an inner diameter of $5 \mathrm{~mm}$ and a length of $50 \mathrm{~mm}$.

The preliminary pyrolysis experimental program was performed at the following operating parameter values:

- atmospheric pressure;

- temperature in the isothermal reaction zone: $460{ }^{\circ} \mathrm{C}$;

- liquid hourly space velocity (LHSV): $0.33 \mathrm{~h}^{-1}$.

To achieve the thermocatalytic process, a superacid catalyst and a Cu-based catalyst were selected. The acid type catalyst was obtained in situ by condensation of the phosphoric acid at the reaction temperature. The $\mathrm{Cu}$ catalyst was prepared starting from a precursor of copper salt with acetic acid by precipitation at $\mathrm{pH} 10$, in the presence of Pluronic $\mathrm{P} 123$ to prevent agglomeration of the metallic active centers. The dimensions of the copper catalyst particles and the distribution of their dimensions were determined using a Dynamic Light Diffusion (DLS) particle size measurement system with a Malvern-Zetasizer NanoZS (Red Badge) instrument. Concentration of the catalytic precursors to conditioned digestate was $2 \%$ by weight.

The composition of the liquid fraction resulting from the pyrolysis was determined with a GC-MS/MS TRIPLE QUAD (Agilent 7890 A) equipped with a DB-WAX capillary column ( $30 \mathrm{~m}$ length, $0.25 \mathrm{~mm}$ internal diameter, $0.25 \mu \mathrm{m}$ film thickness) and helium as carrier gas at one $\mathrm{mL} / \mathrm{min}$. The oven temperature was initially set at $70^{\circ} \mathrm{C}$ and then increased to $230^{\circ} \mathrm{C}$ with a rate of $4^{\circ} \mathrm{C} / \mathrm{min}$ and hold time of $5 \mathrm{~min}$. The GC injector and MS ion source temperatures were 250 and $150^{\circ} \mathrm{C}$, respectively. The transfer line temperature was $280^{\circ} \mathrm{C}$. The MS detector was operated in El mode at $70 \mathrm{eV}$, with a $\mathrm{m} / \mathrm{z}$ scanning range of 50-450. The FAME peaks in the sample were identified using NIST MS database.

The structural characterization of the biocoal was achieved by textural analysis and determination of ash content. The textural characteristics were determined by isothermal sorption measurements at 77K using a NOVA 2200e-Quantachrome Analyzer porosimeter. The textural parameters were evaluated as follows: the specific surface was calculated from the linear portion of the adsorption isotherm using the BET equation (Brunauer-Emmett-Teller). The total pore volume was estimated from the amount of $\mathrm{N} 2$ adsorbed at the relative pressure $\mathrm{p} / \mathrm{po} \sim 0.9$. The pore size distribution was obtained from the absorption or desorption branch, preferably desorption of the isotherm using the BJH method (Barrett-Joyner-Halenda). Determination of ash content was performed by the thermogravimetric method with a DuPont Instruments Thermal Analyst 2000/2100 coupled with a 951 Thermogravimetric Analyzermodule, in inert gas (nitrogen) or synthetic air, with a flow rate of $50 \mathrm{~mL} / \mathrm{min}$, sample mass analyzed approx. $5 \mathrm{mg}$, heating rate $10^{\circ} \mathrm{C} / \mathrm{min}$, heating from room temperature to $700^{\circ} \mathrm{C}$.

\section{Results and discussions}

The DLS analysis of the catalyst based on $\mathrm{Cu}$ is shown in Figure 1 . From this figure it is observed that particles obtained after precipitation of $\mathrm{Cu}$ acetate in the presence of Pluronic P123 have dimensions in three areas (trimodal

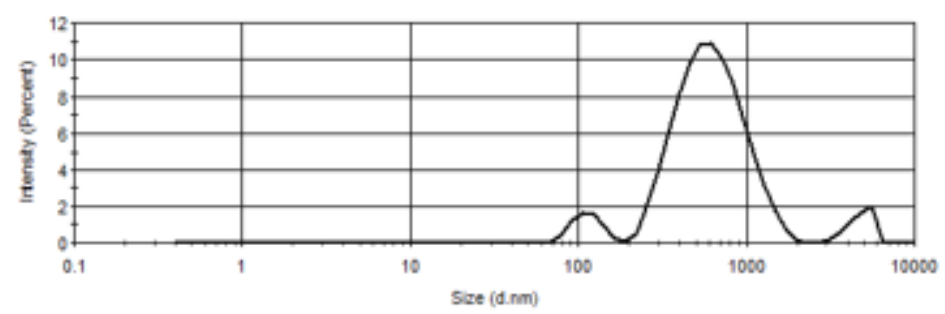

Fig.1. Distribution of the particle size of Cu catalyst precipitated in the presence of Pluronic P123

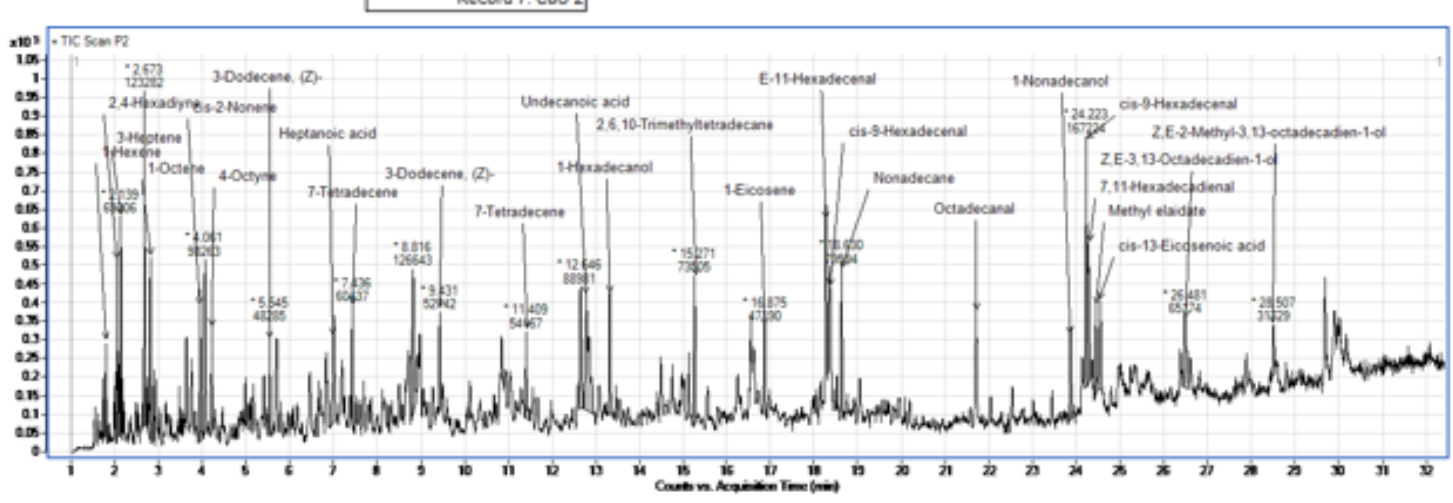

Fig. 2. The composition of the organic liquid phase separated from the catalytic pyrolysis in the presence of catalyst based on $\mathrm{Cu}$ 


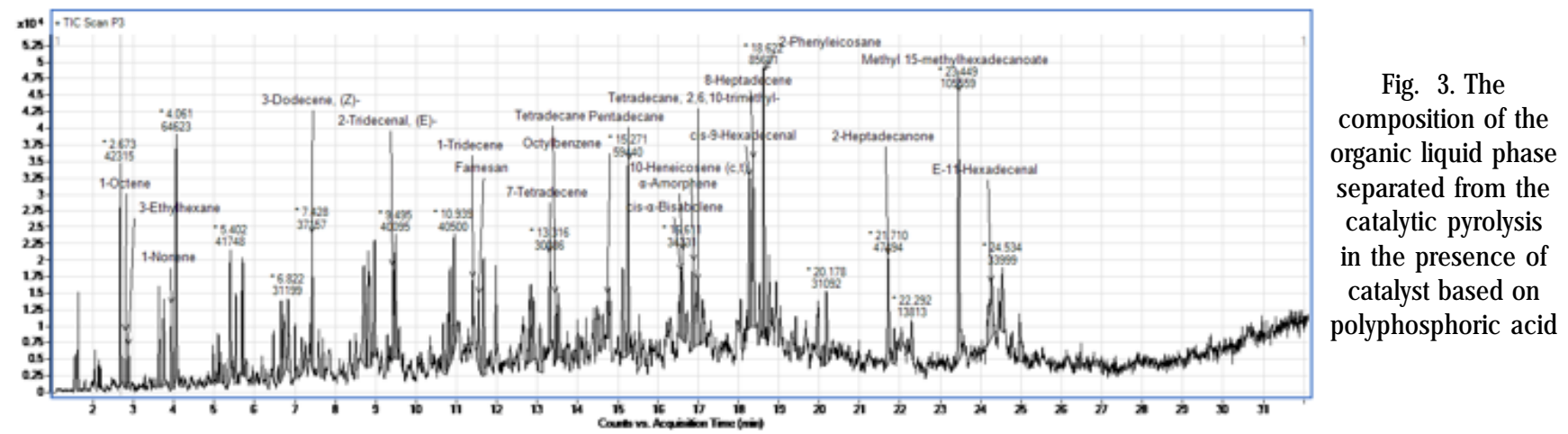

\begin{tabular}{|c|c|c|c|}
\hline Coal & $\begin{array}{c}\text { SEET, } \\
\mathbf{m}^{2} / \mathbf{g}\end{array}$ & $\begin{array}{c}\text { Pore volume, } \\
\mathbf{c m}^{3} / \mathbf{g}\end{array}$ & $\begin{array}{c}\text { Average pore } \\
\text { diameter, } \mathbf{n m}\end{array}$ \\
\hline Coal from Cu catalyst & 4.818 & 0.006 & 3.250 \\
\hline Coal from polyphosphoric acid catalyst & 5.228 & 0.007 & 3.476 \\
\hline
\end{tabular}

Table 2

TEXTURAL PROPERTIES OF THE COALS
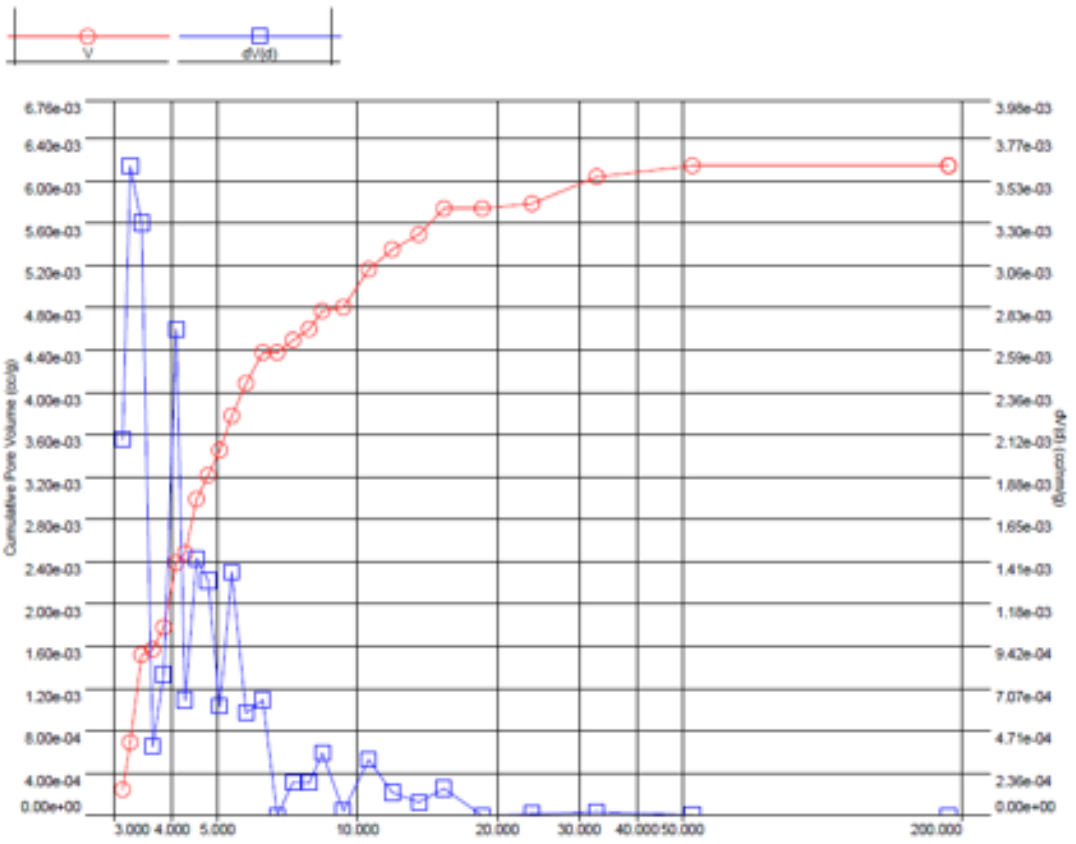

Fig. 4. Pore size distribution for the coal obtained in the presence of $\mathrm{Cu}$ catalyst

Fig. 5. Pore size distribution for the coal obtained in the presence of

polyphosphoric acid catalyst

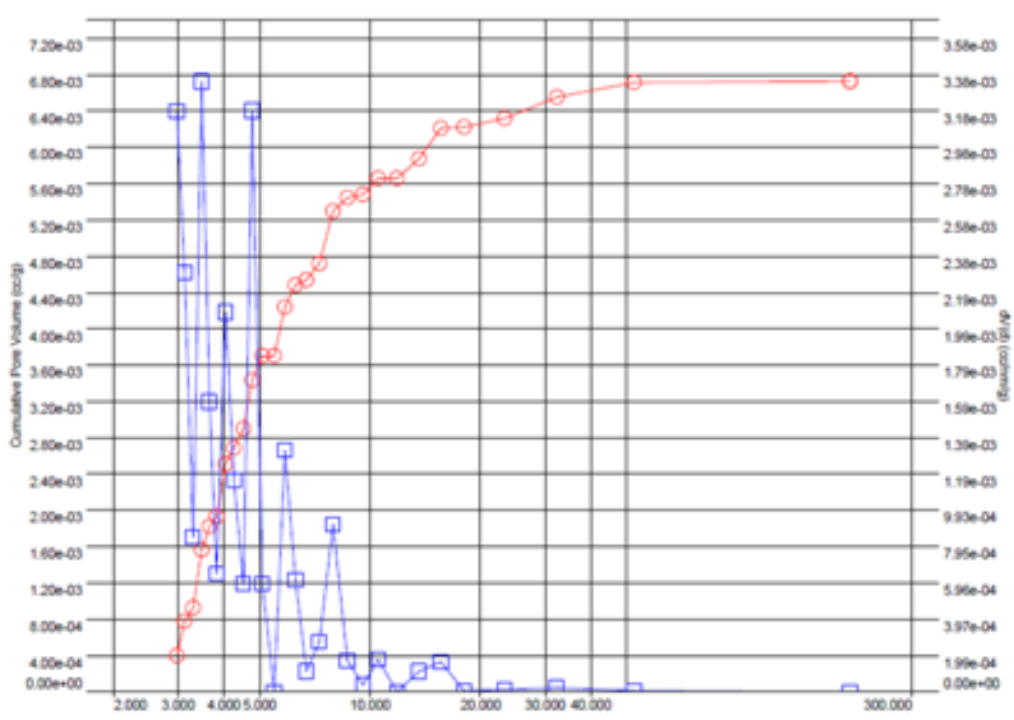

particle size distribution), most of them having dimensions between 100 and $1100 \mathrm{~nm}$, with a maximum dimension of $664 \mathrm{~nm}$.
Figures 2 and 3 present the chromatograms of liquid phase compositions separated during the catalytic pyrolysis process in the presence of Cu and polyphosphoric acid, respectively. The analysis of the two chromatograms 


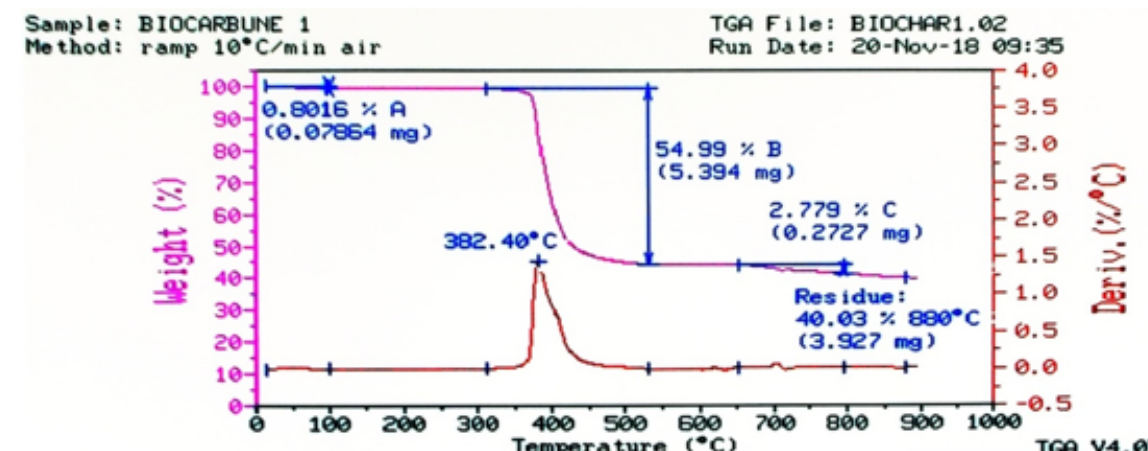

Fig. 6. Ash content of bio-coal obtained on the Cu catalyst

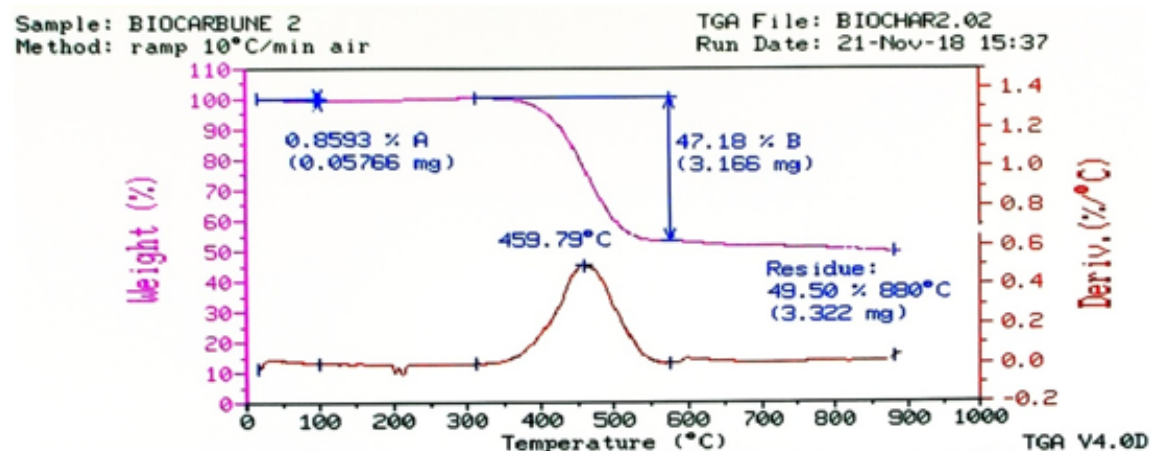

Fig. 7. Ash content of bio-coal obtained on the polyphosphoric acid catalyst

reveals a close composition of the liquid tractions obtained on the two catalysts, which differ by the presence of a higher concentration of branched isomers in the case of the polyphosphoric acid catalyst. This highlights the presence of a large number of linear and branched aliphatic hydrocarbon components, unsaturated compounds, alcohols, carbonyl compounds and fatty acids or methyl esters thereof, with boiling temperatures ranging over a wide range of compounds exhibiting different reactivities.

Textural caracteristics of the separated coal in the catalytic pyrolysis process in the presence of the $\mathrm{Cu}$ and polyphosphoric acid catalysts are summarized in Table 2.

The coals obtained on both catalysts show a low pores volume and implicitly a small specific surface specific to the unactivated carbon.

The distribution of pore size for the coal obtained in the presence of the two catalysts (Cu and polyphosphoric acid) is shown in Figures 4 and 5 . Mesopore size distribution of the coal obtained with the both catalystsis between 3 and $20 \mathrm{~nm}$.

The tw o coals exhibits similar isotherms of adsorption (Figure 4 and 5), specific to mesoporous solids. The appearance of the desorption curve indicates the presence of low-volatile compounds adsorbed in the pores of the two coals obtained, which may be due to an inefficient degassing caused by the presence of tar in unactivated coals.

The ash content of the bio-coal obtained on the polyphosphoric acid catalyst was higher by almost $25 \%$ compared to the bio-carbon obtained on the Cu catalyst (Figure 6 and 7). The presence of the polyphosphoric acid has favored an advanced condensation of biomass and implicitly a diminution of bio-coal oxidative decomposition process.

\section{Conclusions}

The pyrolysis of the digestate suspended in a reverse emulsion was carried out in a continuous system, in a quart tubular reactor, at atmospheric pressure, $460^{\circ} \mathrm{C}$ and liquid hourly space velocity of $0.33 \mathrm{~h}^{-1}$, in the presence of Cu and polyphosphoric acid.

The composition of the liquid fractions obtained on the two catalysts differ by the presence of a higher concentration of branched isomers in the case of the polyphosphoric acid catalyst. This highlights the presence of a large number of linear and branched aliphatic hydrocarbon components, unsaturated compounds, alcohols, carbonyl compounds and fatty acids or methyl esters.

The coals obtained on both catalysts show a low pores volume and implicitly a small specific surface specific to the unactivated carbon.

The ash content of the bio-coal obtained on the polyphosphoric acid catalyst was higher compared to the bio-carbon obtained on the Cu catalyst.

Acknowledgements: The authors gratefully acknowledge the financial support of the UEFISCDI, Romania, in the framework of PN-III-P1-1.2PCCDI-2017, financing contract no. 32 PCCDI/2018.

\section{References}

1. NAQVI, S.R., JAMSHAID, S., NAQVI, M., FAROOQ, W., NIAZI, M.B.K., AMAN, Z., Renew Sustain Energy Rev.,81, 2018, p.1247

2. GUO, F., LIU, Y., WANG, Y., LI, X., LI, T., GUO, C., Energy Convers Manage. 130, 2016, p.184-91

3. LEE, D-H., Int J. Hydrogen Energy, 42, 2017, p.27701

4. ZHANG, X-Y., Adv.Clim. Change Res., 2016, 7, p. 17

5. POPP, J., LAKNER, Z., HARANGI-RAKOS, M., FARI, M., Renew Sustain Energy Rev.,32, 2014, p.559

6.SAFARA, M., LINC, B.-J ., WEI-HSIN CHENC, LANGAUERA, D., CHANGE, J.-S., RACLAVSKAA, H., PETRISSANSD, A., ROUSSETG, P., PETRISSANSD, M., Applied Energy, 235, 2019, p.346

7. XUN HU, GHOLIZADEH, M., J ournal of Energy Chemistry, 2019, in press, www.elsevier.com/locate/jechem

8. WANG, S., DAI, G., YANG. H., LUO, Z., Prog. Energy. Combust. Sci., 62,2017, p.33

9. MOHAN, D., PITTMAN, C.U., STEELE, P.H., Energy Fuels, 20,2006, p.848

10. BRIDGWATER, A.V., Biomass Bioenergy, 38, 2012, p.68

11. KAN, T., STREZOV, V., EVANS, T. J., Renewable and Sustainable Energy Reviews, 57, 2016, p. 1126

12. ARNI, S. A., Renewable Energy, 124, 2018,p.197

13. OPRESCU, E.-E., CALIN, C., BOMBOS, M., VASILIEVICI, G., VELEA, S., Use of Ethoxylated Surfactants to Improve Digestate Stability, Rev.Chim.(Bucharest), 70, 2019, in press.

Manuscript received: 13.03 .2019 